\title{
Myocardial viability twenty-four hours after orthotopic heart transplantation from non-heart-beating donors
}

Juergen Martin, MD, a Georg Lutter, MD, ${ }^{\text {a }}$ Christian Ihling, MD, ${ }^{b}$ Matthias Siepe, MD, ${ }^{a}$ Susanne Wagner, BS, ${ }^{a}$ Jan Hilberath, MD, ${ }^{a}$ Michael Kemper, MD, ${ }^{a}$ Koppany Sarai, MD, and Friedhelm Beyersdorf, MD ${ }^{a}$

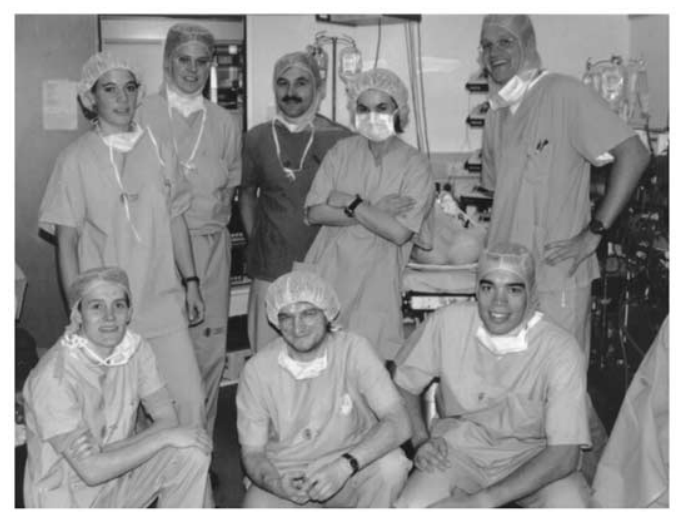

Research team

Objectives: Using a new preservation strategy, we investigated the performance of hearts from non-heart-beating donors during an observation period of 24 hours after orthotopic heart transplantation in a pig model.

Methods: In the control group $(n=6)$ beating donor hearts were harvested with Bretschneider's HTK solution and transplanted orthotopically without reperfusion modifications. In the non-heart-beating donor group $(\mathrm{n}=6)$ hearts were perfused with leukocyte-depleted blood cardioplegia after 30 minutes of normothermic ischemia. Blood cardioplegia was supplemented with a sodium-hydrogen exchange inhibitor and adenosine. After transplantation, a second controlled reperfusion with blood cardioplegia was performed.

Results: Preload recruitable stroke work of the left ventricle 24 hours after transplantation in the control versus non-heart-beating donor group was $108 \% \pm 24 \%$ versus $103 \% \pm 18 \%$ of baseline values. Myocardial blood flow of the left and right ventricle was increased to $146 \% \pm 32 \%$ and $176 \%$ $\pm 51 \%$ in the control group versus $176 \% \pm 29 \%$ and $194 \% \pm 27 \%$ in the non-heart-beating donor group. Myocardial oxygen consumption was $11.2 \pm 2.1$ versus $12.8 \pm 2.2 \mathrm{~mL} / 100 \mathrm{~g}$ per minute at baseline and $11.6 \pm 2.6$ versus $13.2 \pm$ $3.1 \mathrm{~mL} / 100 \mathrm{~g}$ per minute after 24 hours (not significant). Histologic examination with Luxol fast blue staining revealed that $2.6 \% \pm 4.8 \%$ of myocytes in the control group versus $1.8 \% \pm 1.9 \%$ in the non-heart-beating donor group were damaged irreversibly.

From the Department of Cardiovascular Surgery ${ }^{\mathrm{a}}$ and the Institute of Pathological Anatomy, ${ }^{\mathrm{b}}$ Albert-Ludwigs-University Medical Center, Freiburg, Germany.

Supported by the Clinical Research Center II of the Albert-Ludwigs-University Freiburg, grant No B4. HOE 642 was a gift of Hoechst AG, Frankfurt/Main, Germany. Leukocyte filters were a gift of Pall GmbH, Dreieich, Germany.

Read at the Eighty-second Annual Meeting of The American Association for Thoracic Surgery, Washington, DC, May 5-8, 2002.

Received for publication May 29, 2002; revisions requested July 30, 2002; revisions received Aug 7, 2002; accepted for publication Aug 15, 2002.

Address for reprints: Juergen Martin, MD, Department of Cardiovascular Surgery, Albert-Ludwigs-University, Hugstetter Str 55, D-79106 Freiburg, Germany (E-mail: Martin@ch11.ukl.uni-freiburg.de).

J Thorac Cardiovasc Surg 2003;125: 1217-28

Copyright $(\odot 2003$ by The American Association for Thoracic Surgery

$0022-5223 / 2003 \$ 30.00+0$

doi:10.1016/S0022-5223(02)73234-0
Conclusions: Recovery of donor hearts from non-heart-beating donors is comparable with recovery of organs harvested from heart-beating donors if the abovementioned preservation technique is used. These results could encourage the use of marginal donor hearts and help to expand the limited donor pool.

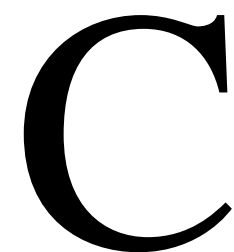

urrently, the worldwide decreasing number of heart transplantations resulting from an increasing lack of donor organs remains the major problem in heart transplantation. ${ }^{1}$

The use of marginal donors could help to expand the donor pool. Furthermore, hearts with prolonged ischemia times ( $>4$ hours) and hearts from non-heart-beating donors (NHBDs) could be a source of additional donor organs. At present, these hearts are usually rejected in consideration of an increased risk of primary graft failure.

Previous studies in the pig model by our group have shown that successful heart transplantation from NHBDs after 30 minutes of normothermic ischemia is possible if controlled reperfusion with blood cardioplegia is performed along with some new reperfusion modalities. ${ }^{2,3}$ These modalities include leukocyte depletion, supplementation with the sodium-hydrogen exchange inhibitor HOE 642, and start of reperfusion with tepid instead of normothermic blood cardioplegia. Despite encouraging results in these short-term experiments, cardiac output of the hearts was severely 
impaired, and irreversible myocardial damage could not be excluded. Therefore further experiments with longer observation times seemed to be necessary.

The purpose of this study was to evaluate the performance of hearts harvested from NHBDs 24 hours after transplantation in comparison with control hearts. The registration of pressure-volume loops by using the conductance catheter method provided a detailed analysis of myocardial contractility. In addition, measurements of regional myocardial perfusion, metabolic parameters (eg, oxygen consumption), and quantification of myocardial damage by means of histologic examinations enabled complex assessment of these hearts.

Further refinements of the myocardial protection strategy were introduced to minimize ischemia-reperfusion damage. First, blood cardioplegia was supplemented with adenosine. Adenosine has potent cardioprotective properties involving metabolic changes, inhibition of neutrophils, and relaxation of vasculature. ${ }^{4}$ Second, controlled reperfusions with blood cardioplegia were performed after completion of each anastomosis to reduce ischemic damage during implantation of the donor heart.

\section{Materials and Methods}

\section{Animals and Anesthesia}

All procedures were performed in conformity with the "Guide for the Care and Use of Laboratory Animals" and the German "Law on the Protection of Animals." Pigs of the German Landrace weighing $34.5 \pm 5.0 \mathrm{~kg}$ were premedicated with an intramuscular injection of $0.2 \mathrm{mg} / \mathrm{kg}$ flunitrazepam and $7 \mathrm{mg} / \mathrm{kg}$ ketamine hydrochloride. An ear vein was cannulated, and anesthesia was induced with $0.1 \mathrm{mg} / \mathrm{kg}$ flunitrazepam and $10 \mathrm{mg} / \mathrm{kg}$ ketamine hydrochloride by means of titrated intravenous injection. An endotracheal tube was inserted, and mechanical ventilation was begun. Catheters were introduced into the carotid artery and internal jugular vein to measure arterial pressure, central venous pressure, pulmonary artery pressure, and cardiac output.

\section{Surgical Procedure}

After median sternotomy, $500 \mathrm{IE} / \mathrm{kg}$ heparin was given to all pigs. A 7F polyurethane catheter was inserted into the left atrium through the left atrial appendage to monitor left atrial pressure. A 12-gauge cannula was placed into the ascending aorta of the donor hearts for application of cardioplegia. This cannula was also used for exsanguination of the animals. After procurement, the donor hearts were stored in ice-cold cardioplegic solution.

Cardiopulmonary bypass. The heart-lung machine (Stöckert, Munich, Germany) was filled with a priming of $1000 \mathrm{~mL}$ of hydroxyethyl starch. We used a pediatric oxygenator (D705; Dideco, Mirandola, Italy), systemic heater-cooler (Jostra, Hirrlingen, Germany), and arterial filter (D733, Dideco). Cannulation of the ascending aorta was performed by using a $16 \mathrm{~F}$ aortic cannula. Cannulation of the superior and inferior venae cavae was achieved through the right atrium with $20 \mathrm{~F}$ and $28 \mathrm{~F}$ cannulas. A $9 \mathrm{~F}$ vent catheter was inserted into the left atrium to avoid distention of the left ventricle. The blood flow was 2.2 to $2.5 \mathrm{~L} / \mathrm{min}$.
Orthotopic heart transplantation. Transplantation was performed in a biatrial technique. The left azygos vein, a special feature of the porcine anatomy, was dissected in the donor. Left azygos vein and the coronary sinus of the recipient remained intact. A small catheter was placed in the coronary sinus of the donor heart to obtain blood samples for metabolic investigations.

At the end of the experiment, the animals were killed by means of an intravenous injection of potassium chloride.

Control group $(n=6)$. Hearts were harvested in a clinically comparable manner. Cardiac arrest was induced by $1500 \mathrm{~mL}$ of Bretschneider's HTK solution (Custodiol; Dr Franz Köhler, Chemie $\mathrm{GmbH}$, Alsbach-Hähnlein, Germany; $4^{\circ} \mathrm{C}$; perfusion pressure $40-50 \mathrm{~mm} \mathrm{Hg}$ ) applied through the aortic root. The hearts were stored for 3 hours in ice-cooled HTK solution and transplanted orthotopically. No reperfusion modifications were used in this group.

NHBD group $(n=6)$. Circulatory arrest was induced by means of exsanguination. After zero blood pressure, the animals were left undisturbed for 30 minutes. The hearts were beating empty, heart frequency decreased continuously, and complete cardiac arrest was observed 8 to 12 minutes after zero blood pressure.

Thereafter, controlled reperfusion with $1000 \mathrm{~mL}$ of blood cardioplegia (blood cardioplegic solution for controlled reperfusion; Dr Franz Köhler, Chemie GmbH, Germany) was performed through the aortic root (temperature of $10^{\circ} \mathrm{C}-15^{\circ} \mathrm{C}$, perfusion pressure of $40 \mathrm{~mm} \mathrm{Hg}$ ). Blood cardioplegia was leukocyte depleted (Pall BC1; Pall GmbH, Dreieich, Germany) and supplemented with $379 \mathrm{mg} / \mathrm{L}$ HOE 642 (Hoechst AG, Frankfurt, Germany) and $100 \mathrm{mg} / \mathrm{L}$ adenosine (Sigma-Aldrich). Hearts were excised, stored in ice-cold blood cardioplegic solution for 3 hours, and transplanted orthotopically. During implantation, controlled reperfusion with $300 \mathrm{~mL}$ of leukocyte-depleted blood cardioplegia $\left(20^{\circ} \mathrm{C}\right.$ at 40 $\mathrm{mm} \mathrm{Hg}$ ) through the aortic root was performed after completion of each anastomosis. Blood cardioplegia was supplemented with HOE 642 and adenosine. After completion of the last anastomosis, controlled reperfusion was continued with leukocyte-depleted blood for 20 minutes. The temperature of reperfusate was $25^{\circ} \mathrm{C}$ initially and was stepwise increased to $37^{\circ} \mathrm{C}$ after 20 minutes before the aortic clamp was released. After the start of reperfusion, adenosine at $140 \mu \mathrm{g} \times \mathrm{kg}^{-1} \times \mathrm{min}^{-1}$ was administered intravenously for 60 minutes.

In both groups weaning from cardiopulmonary bypass was attempted 60 minutes after the start of reperfusion. For inotropic support, $0.1 \mu \mathrm{g} \times \mathrm{kg}^{-1} \times \mathrm{min}^{-1}$ epinephrine was administered.

\section{Hemodynamic Measurements}

Cardiac output was measured by using the thermodilution technique.

Pressure-volume loops were registered by using the conductance catheter technique (Leycom CFL 512; CD Leycom, Zoetermeer, The Netherlands). A 7F pigtail conductance catheter (electrode spacing of $8 \mathrm{~mm}$; Sentron, Roden, The Netherlands) and a 3F pressure-tip catheter (Millar, Houston, Tex) were introduced through apical incisions of the left and right ventricle. Hemodynamic parameters (dp/dt, end-systolic elastance, and preload recruitable stroke work [PRSW]) were calculated by using Leycom CFL software. 


\section{Regional Myocardial Blood Flow}

Regional myocardial blood flow (RMBF) was measured with fluorescent microspheres. Through a polyurethane cannula, $1.5 \mathrm{~mL}$ $\left(1.5 \times 10^{6}\right)$ of fluorescent polystyrene microspheres (diameter of $15 \mu \mathrm{m}$; fluorescent labels: orange, blue-green, and red; Molecular Probes, Eugene, Ore) mixed with $8.5 \mathrm{~mL}$ of heparinized fresh blood was injected into the left atrium. The injection was performed over a period of 60 seconds.

A reference blood sample was taken from the ascending aorta. Aspiration of the reference sample (withdrawal rate, $7.5 \mathrm{~mL} / \mathrm{min}$ ) was started 15 seconds before application of the microspheres and was continued for 45 seconds after completion of the injection.

Tissue and blood digestion. From each heart, midventricular slices were obtained from the left $(n=4)$ and right $(n=4)$ ventricular wall and from the septum $(n=4)$. The ventricular samples were divided into a subendocardial and subepicardial specimen. Each of the 20 samples was weighed (Precision Weigher; Sartorius GmbH, Göttingen, Germany). The mean wet weight of the tissue samples was $0.9 \pm 0.2 \mathrm{~g}$. Processing of FMS was performed by using the so-called sedimentation technique. .,6 $^{-6}$

Measurement of fluorescence. Fluorescence was determined with a luminescence spectrophotometer (Perkin Elmer 650-10LC, Überlingen, Germany) with an excitation wavelength of 427 to 570 $\mathrm{nm}$ and an emission wavelength of 468 to $598 \mathrm{~nm}$.

Calculation of myocardial blood flow. The fluorescent signal in the solution is directly proportional to the number of microspheres present in the sample. Flow to each tissue piece was calculated by using the following formula:

$$
\mathrm{Q}_{\mathrm{x}}=\left(\mathrm{Flu}_{\mathrm{x}} / \mathrm{Flu}_{\mathrm{ref}}\right) \times \mathrm{Q}_{\mathrm{ref}},
$$

where $Q_{x}$ is defined as blood flow in the tissue sample (in milliliters per gram times minutes), $\mathrm{Q}_{\mathrm{ref}}$ is defined as the withdrawal rate of the reference blood sample (in milliliters per minute), Flu is defined as fluorescence intensity in the tissue sample (in units per milliliter), and $\mathrm{Flu}_{\mathrm{ref}}$ is defined as fluorescence intensity in the reference blood sample (in units per milliliter).

\section{Metabolic Parameters}

Blood samples were obtained from the arterial blood, blood cardioplegia, and coronary sinus to measure blood gases and glucose and lactate concentrations (ABL System 625/AS 117; Radiometer Medical, Copenhagen, Denmark).

Myocardial oxygen consumption was calculated by using the following equation:

$$
\mathrm{MVO}_{2}=(\mathrm{A}-\mathrm{V}) \times \mathrm{MBF},
$$

where $\mathrm{MVO}_{2}$ is defined as myocardial oxygen consumption (in milliliters per 100 grams per minute), $\mathrm{A}$ is defined as arterial oxygen concentration (milliliters of oxygen per milliliter of blood), $\mathrm{V}$ is defined as coronary sinus oxygen concentration (in milliliters of oxygen per milliliter of blood), and MBF is defined as myocardial blood flow (in milliliters per 100 grams per minute).

For calculation of oxygen consumption at baseline and 4 and 24 hours after transplantation, total myocardial blood flow was derived from regional myocardial blood flow, according to the ratio of left ventricular/right ventricular/septal heart weight $(0.65 / 0.25$ / 0.1 ). This ratio was determined by means of postmortem exami- nations of the hearts. Of course, this method provides only an approximate calculation of total myocardial blood flow.

Extraction of oxygen, glucose, and lactate was calculated by using the following equation:

$$
\mathrm{E}=\frac{\mathrm{A}-\mathrm{V}}{\mathrm{A}} \times 100 \%
$$

where $\mathrm{E}$ is defined as the extraction quotient (in percentage), $\mathrm{A}$ is defined as the arterial substrate concentration, and $\mathrm{V}$ is defined as the coronary sinus substrate concentration.

\section{Myocardial Specific Enzymes}

The routine test for assessment of creatine kinase MB (CK-MB) does not produce reliable data in pigs. ${ }^{3}$ Therefore we used an agarose electrophoresis test (REP-CK/LD-isoenzyme combo method; Helena Laboratories, Beaumont, Tex). This test analyses the percentage of CK-MB in relation to the total CK. Total CK was measured photometrically with an enzymatic test (CK [NAC] AU 5000 Analyser System; Merck, Darmstadt, Germany).

\section{Histologic Examinations}

Specimens of the left midventricular wall were embedded in paraffin and stained with hematoxylin-eosin and Luxol fast blue. Luxol fast blue staining provides a safe identification of irreversibly damaged myocardium. Therefore the ratio of damaged myocytes in relation to normal myocytes was assessed in 10 highpower fields at 40 -fold magnification by 2 blinded observers.

\section{Statistical Analysis}

Statistical analysis was performed with a statistical computer program (Prism; Graph Pad Software, San Diego, Calif). Group statistics were expressed as means \pm SD.

Two-group comparisons of the posttransplant values with the baseline values, subendocardial versus subepicardial RMBF, and left ventricle versus right ventricle were made by running a paired $t$ test with a 2-tailed $P$ value. For analysis of repeated measures of one variable, a repeated measures analysis of variance was used. Intergroup comparisons were performed by using an unpaired $t$ test.

\section{Results}

\section{Ischemic Time}

Total ischemic time was $223 \pm 33$ minutes in the control group and $243 \pm 24$ minutes in the NHBD group (not significant). Cold ischemic time was $162 \pm 33$ minutes in the control group and $151 \pm 16$ minutes in the NHBD group (not significant).

\section{Time for Weaning}

All animals could be weaned from cardiopulmonary bypass after $58 \pm 28$ minutes in the control group and $74 \pm 18$ minutes in the NHBD group (not significant).

\section{Hemodynamics}

Data on henodynamics are shown in Tables 1 and 2. Hemodynamics remained stable throughout the observation 
TABLE 1. Hemodynamic parameters at baseline and after heart transplantation

\begin{tabular}{|c|c|c|c|c|c|c|}
\hline & \multicolumn{3}{|c|}{ Control group $(n=6)$} & \multicolumn{3}{|c|}{ NHBD group $(n=6)$} \\
\hline & Baseline & $4 \mathrm{~h}$ & $24 \mathrm{~h}$ & Baseline & $4 \mathrm{~h}$ & $24 \mathrm{~h}$ \\
\hline $\mathrm{CO}$ (L/min) & $5.4 \pm 0.8$ & $2.9 \pm 0.1^{*}$ & $2.6 \pm 0.3^{*}$ & $4.2 \pm 0.7 \dagger$ & $2.3 \pm 0.4^{*}$ & $2.8 \pm 0.5^{*}$ \\
\hline $\mathrm{HR}\left(\min ^{-1}\right)$ & $97 \pm 19$ & $137 \pm 6^{*}$ & $162 \pm 15^{*} \ddagger$ & $86 \pm 15$ & $157 \pm 12^{*}$ & $143 \pm 11^{*} \dagger$ \\
\hline $\mathrm{CVP}(\mathrm{mm} \mathrm{Hg})$ & $2.6 \pm 1.8$ & $7.4 \pm 1.9^{*}$ & $8.8 \pm 3.8^{*}$ & $5.7 \pm 4.1$ & $9.5 \pm 6.6^{*}$ & $9.7 \pm 5.2^{*}$ \\
\hline $\mathrm{LAP}(\mathrm{mm} \mathrm{Hg})$ & $6.4 \pm 0.8$ & $6.3 \pm 1.4$ & $8.6 \pm 1.6^{*}$ & $6.7 \pm 0.8$ & $6.8 \pm 1.0$ & $8.8 \pm 1.6^{*}$ \\
\hline MAP (mm Hg) & $82 \pm 22$ & $88 \pm 16$ & $94 \pm 14$ & $88 \pm 17$ & $92 \pm 12$ & $103 \pm 16$ \\
\hline PAP (mm Hg) & $19 \pm 2$ & $23 \pm 3$ & $20 \pm 3$ & $16 \pm 3$ & $20 \pm 8$ & $20 \pm 4$ \\
\hline $\begin{array}{l}\text { SVR } \\
\quad\left(\text { dynes } \cdot \mathrm{s}^{-1} \cdot \mathrm{cm}^{-5}\right)\end{array}$ & $1176 \pm 134$ & $2223 \pm 254^{*}$ & $2622 \pm 306^{*}$ & $1568 \pm 176$ & $2869 \pm 304^{*} \dagger$ & $2666 \pm 326^{*}$ \\
\hline $\begin{array}{l}\text { PVR } \\
\quad\left(\text { dynes } \cdot \mathrm{s}^{-1} \cdot \mathrm{cm}^{-5}\right)\end{array}$ & $191 \pm 38$ & $439 \pm 57^{*}$ & $351 \pm 49^{*}$ & $177 \pm 32$ & $459 \pm 95^{*}$ & $320 \pm 71^{*}$ \\
\hline
\end{tabular}

Data are given as mean \pm SD. $C O$, Cardiac output; $H R$, heart rate; $C V P$, central venous pressure; $L A P$, left atrial pressure; $M A P$, mean arterial pressure; $P A P$, mean pulmonary artery pressure; $S V R$, systemic vascular resistance; $P V R$, pulmonary vascular resistance.

${ }^{*} P<.05$ versus baseline.

$\dagger P<.05,4$ hours versus 24 hours.

TABLE 2. Systolic and diastolic parameters and PRSW at baseline and 24 hours after transplantation, as measured by using the conductance catheter technique

\begin{tabular}{|c|c|c|c|c|}
\hline & \multicolumn{2}{|c|}{ Control group } & \multicolumn{2}{|c|}{ NHBD group } \\
\hline & Baseline & $24 \mathrm{~h}$ & Baseline & $24 \mathrm{~h}$ \\
\hline LV dp/dtmax (mm Hg/s) & $1942 \pm 562$ & $1800 \pm 452$ & $1764 \pm 436$ & $2340 \pm 751$ \\
\hline LV dp/dtmin (mm Hg/s) & $1875 \pm 539$ & $1924 \pm 500$ & $1986 \pm 531$ & $2198 \pm 600$ \\
\hline $\mathrm{RV}$ dp/dtmax (mm Hg/s) & $533 \pm 111$ & $494 \pm 134$ & $609 \pm 200$ & $802 \pm 412$ \\
\hline $\mathrm{RV} \mathrm{dp} / \mathrm{dtmin}(\mathrm{mm} \mathrm{Hg} / \mathrm{s})$ & $424 \pm 111$ & $448 \pm 140$ & $384 \pm 78$ & $462 \pm 101$ \\
\hline LV PRSW $\left(\mathrm{erg} \times 10^{3} / \mathrm{mL}\right)$ & $68.0 \pm 12.4$ & $73.5 \pm 16.1$ & $64.3 \pm 10.1$ & $66.5 \pm 11.3$ \\
\hline RV PRSW (erg $\left.\times 10^{3} / \mathrm{mL}\right)$ & $10.0 \pm 3.8$ & $21.8 \pm 5.2^{*}$ & $11.8 \pm 3.3$ & $20.9 \pm 6.0^{*}$ \\
\hline LV EF (\%) & $54.5 \pm 5.2$ & $27.5 \pm 7.7^{*}$ & $54.7 \pm 5.8$ & $37.2 \pm 8.6^{*}$ \\
\hline RV EF (\%) & $59.5 \pm 6.2$ & $32.3 \pm 8.3^{*}$ & $53.2 \pm 9.2$ & $32.5 \pm 6.8^{*}$ \\
\hline LV Ees $(\mathrm{mm} \mathrm{Hg} / \mathrm{mL})$ & $3.4 \pm 0.8$ & $3.3 \pm 0.9$ & $3.3 \pm 0.5$ & $3.1 \pm 0.6$ \\
\hline $\mathrm{RV} \operatorname{Ees}(\mathrm{mm} \mathrm{Hg} / \mathrm{mL})$ & $0.35 \pm 0.08$ & $1.05 \pm 0.29^{*}$ & $0.38 \pm 0.12$ & $1.17 \pm 0.24^{*}$ \\
\hline
\end{tabular}

$L V$, Left ventricle; $R V$, right ventricle; $d p / d t m a x$ and $d p / d t m i n$, maximum and minimum of first derivative of pressure; $E F$, ejection fraction.

${ }^{*} P<.05$ versus baseline.

period of 24 hours. For inotropic support, $0.1 \mu \mathrm{g} \times \mathrm{kg}^{-1} \times$ $\min ^{-1}$ of epinephrine was given.

The baseline data and hemodynamic assessments after transplantation are summarized in Table 1.

In both groups cardiac output and ejection fraction of both ventricles after transplantation were significantly impaired compared with baseline values. Differences between the groups after transplantation were not significant. Heart rate, left atrial and central venous pressure, and systemic vascular and pulmonary vascular resistance were significantly increased after transplantation.

The dp/dtmax and dp/dtmin, left ventricular PRSW, and left ventricular end-systolic elastance (Ees) were not significantly changed 24 hours after transplantation compared with the baseline values (Table 2). In contrast, right ventricular PRSW and Ees were significantly increased in both groups.

\section{Regional Myocardial Blood Flow}

RMBF data are shown in Figure 1. Measurements at baseline revealed homogeneous distribution of blood flow without significant differences between the left ventricle, right ventricle, and septum (Figure 1, A). After transplantation, RMBF was significantly increased in both ventricles but not in the septum (Figure 1, B). Myocardial blood flow in the subendocardial layer was higher compared with that in the subepicardial layer in both ventricles (Figure 1, $C$ and $D$ ). The subendothelial/subepicardial myocardial blood flow ratio did not change significantly over the observation period. Intergroup differences in RMBF were not significant.

\section{Metabolic Parameters}

Data on metabolic parameters are shown in Figures 2 through 5. Myocardial oxygen consumption 4 hours after 

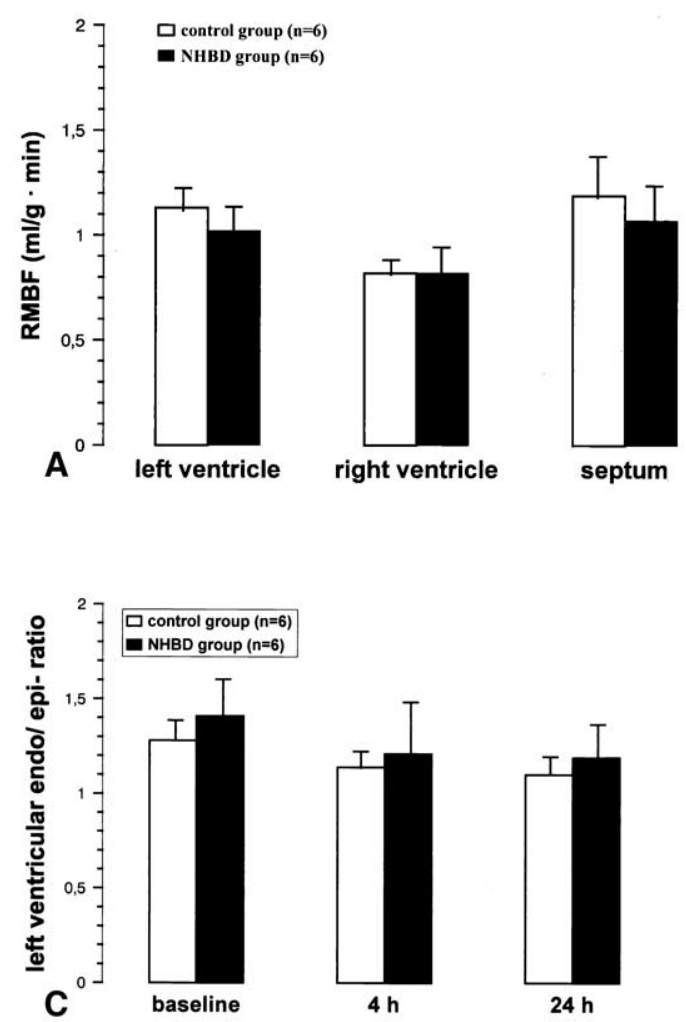

Figure 1. A, RMBF of the donor heart under resting conditions before organ procurement. There were no significant differences between the left ventricle, right ventricle, and septum. There were also no significant intergroup differences. B, RMBF 4 and 24 hours after transplantation in percentage of baseline value. There was a significant increase of RMBF in the left and right ventricle but not in the septum. There were no significant intergroup differences. ${ }^{*} P<.05$ versus baseline. C, Ratio of subendothelial/subepicardial myocardial blood flow (endo/epi ratio) in the left ventricle. There was a slight but not significant decrease of subendothelial/subepicardial myocardial blood flow ratio after 4 and 24 hours in both groups. D, Ratio of subendothelial/subepicardial myocardial blood flow (endo/epi ratio) in the right ventricle. There were no significant changes in both groups.

transplantation was slightly increased compared with baseline values in both groups, but the difference was not significant (Figure 2, A). After 24 hours, oxygen consumption had completely normalized. Intergroup differences were not significant. In the NHBD group oxygen extraction was significantly decreased compared with that seen in the control group 5, 20, 30, and 60 minutes after the start of reperfusion. Thereafter, intergroup differences were not significant (Figure 2, $B$ ).

Because of the substrate enrichment of blood cardioplegia, glucose levels in the arterial blood were significantly increased in the experimental group compared with in the control group within the first 60 minutes after transplantation (Figure 3). In both groups systemic glucose levels remained increased over 24 hours. At baseline, no arteriovenous difference of blood glucose levels could be measured. Within the first 10 minutes after the start of reperfusion, arteriovenous glucose extraction reached negative values in the NHBD group but not in the control group. After 24 hours, glucose extraction was $3.4 \%$ in the control group and $2.4 \%$ in the experimental group. Intergroup differences were significant 1 and 5 minutes after the start of reperfusion.

Systemic lactate levels were significantly higher in the experimental group within the first 60 minutes after the start of reperfusion (Figure 4). In the control group myocardial lactate production could be observed within the first 20 minutes after aortic unclamping. In contrast, the hearts of the NHBD group were able to consume lactate. Intergroup differences were significant during the first 10 minutes only.

Metabolic activity during controlled reperfusions of the donor heart in the NHBD group is shown in Figure 5. Starting the controlled reperfusion in the donor after 30 minutes of normothermic ischemia at a myocardial temperature of $28^{\circ} \mathrm{C}$, oxygen extraction reached greater than $70 \%$, indicating good metabolic activity. At the end of this first reperfusion, myocardial temperature had decreased to $13^{\circ} \mathrm{C}$ before the heart was excised and stored in ice-cold solution. 


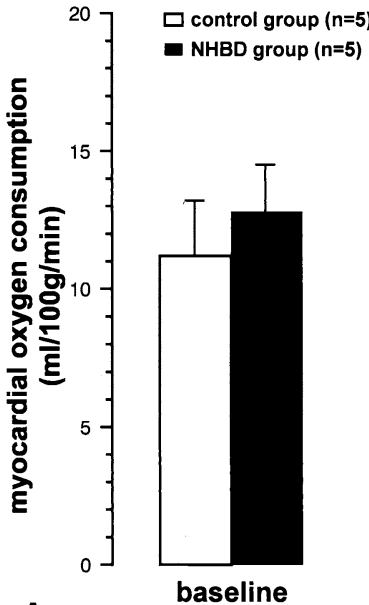

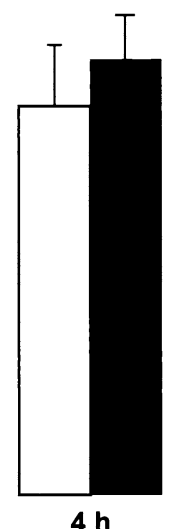

$4 \mathrm{~h}$

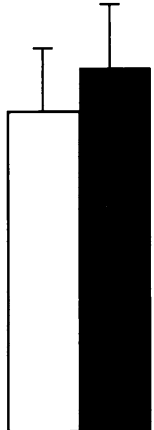

$24 \mathrm{~h}$

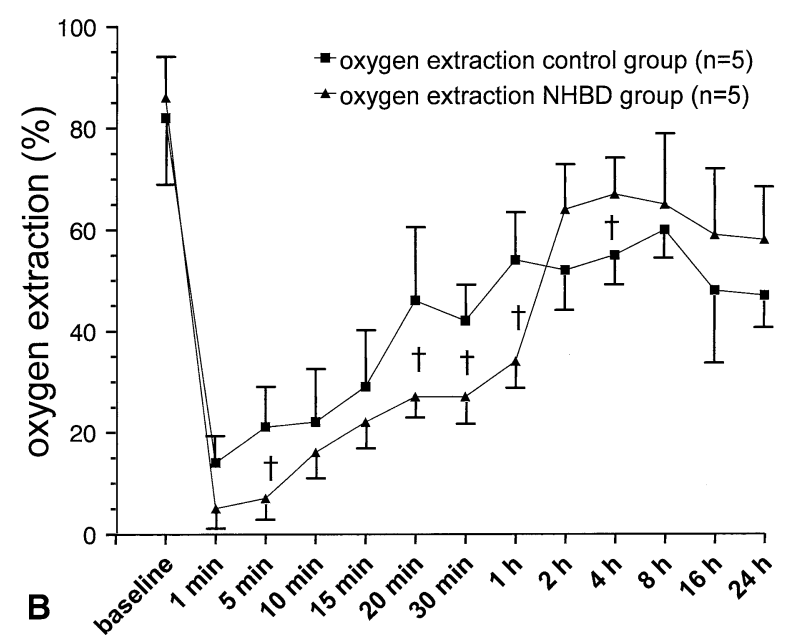

Figure 2. A, Myocardial oxygen consumption at baseline and after heart transplantation. There were no significant changes of oxygen consumption after 4 and 24 hours and no intergroup differences. B, Myocardial oxygen extraction before and after heart transplantation. $+P<.05$, NHBD group versus control group. Measurements were performed before procurement of the donor heart (baseline) and after the start of reperfusion in the recipient (control group, aortic unclamping; NHBD group, hot shot after completion of the last anastomosis). There was decreased oxygen extraction in the experimental group during the first 60 minutes after the start of reperfusion. There were no significant intergroup differences between 1 and 24 hours after heart transplantation.

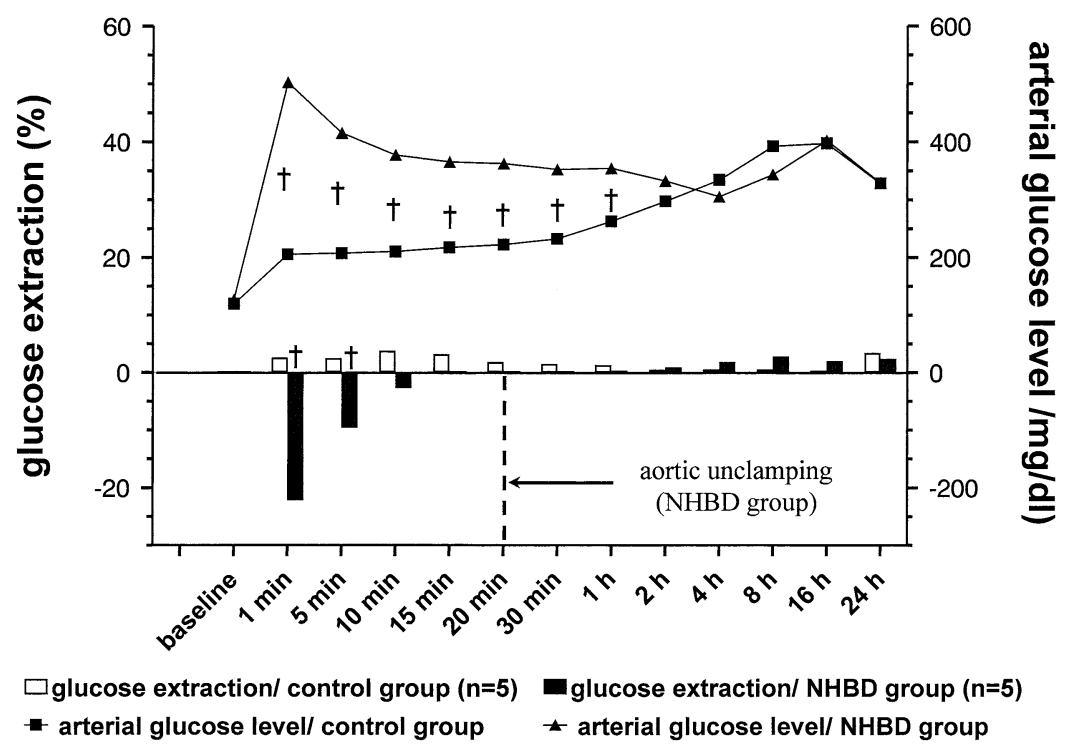

Figure 3. Transmyocardial glucose extraction before and after heart transplantation. $+P<.05$, NHBD group versus control group. There were increased arterial glucose levels in the NHBD group during the first hour of reperfusion. There was glucose release from reperfused myocardium within the first $\mathbf{5}$ minutes after application of hot shot in the experimental group. There were no intergroup differences between 2 and 24 hours after heart transplantation.

Reperfusion in the recipient was started after completion of the first anastomosis at a temperature of $15^{\circ} \mathrm{C}$. Temperature was stepwise increased to $20^{\circ} \mathrm{C}$. Oxygen extraction ranged between $65 \%$ and $75 \%$.

\section{Myocardial Specific CK-MB}

Myocardial specific CK-MD data are given in Figure 6. CK-MB was significantly increased 30 minutes to 24 hours after transplantation in both groups. The CK-MB level 


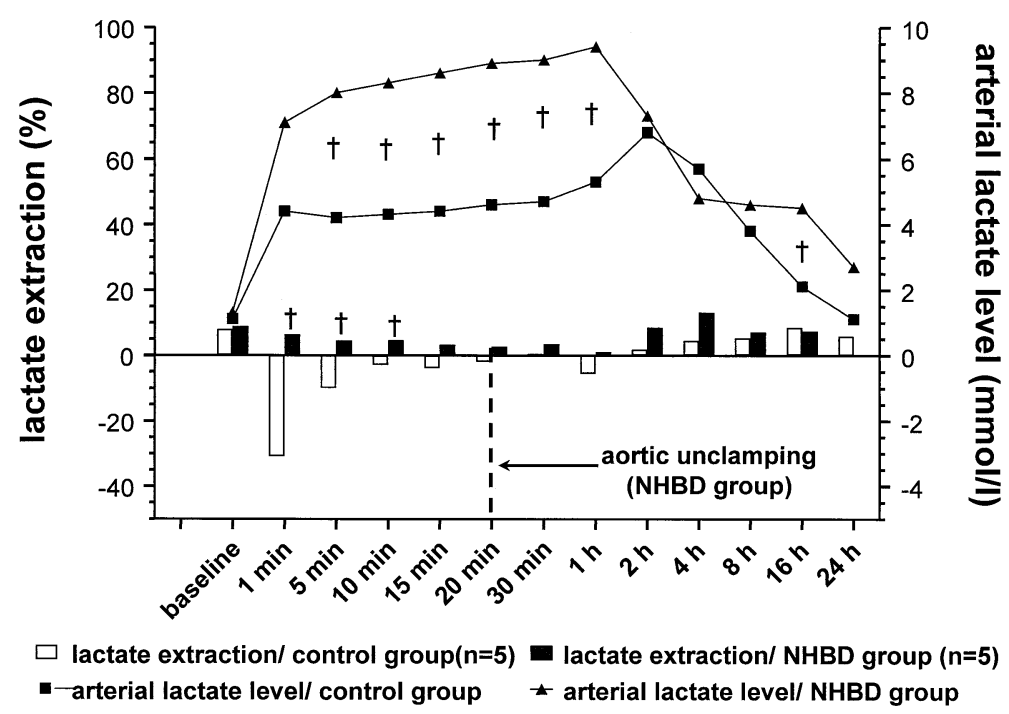

Figure 4. Transmyocardial lactate extraction before and after heart transplantation. $t P<.05$, NHBD group versus control group. There were high lactate levels over 1 hour in the NHBD group. Lactate production in the control group versus lactate consumption in the NHBD group during the first 20 minutes after start of reperfusion is shown.

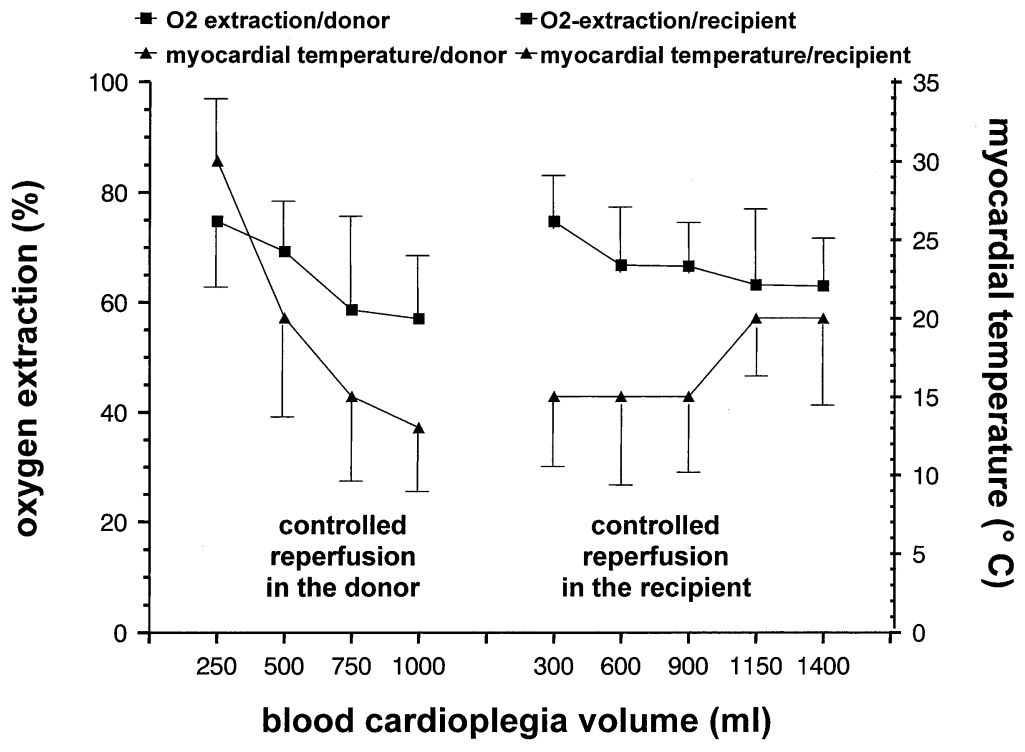

Figure 5. Myocardial oxygen extraction and temperature during controlled reperfusions in the donor (after normothermic ischemia) and in the recipient (after completion of the first anastomosis). There was high oxygen extraction at the start of reperfusion after $\mathbf{3 0}$ minutes of normothermic ischemia, indicating viability of the myocardium.

reached a peak after 2 hours and decreased 24 hours after heart transplantation. Differences between the control and NHBD groups were not significant.

\section{Effectiveness of Leukocyte Filters}

Data on the effectiveness of leukocyte filters are given in Figure 7. Leukocyte counts proximal and distal to the leukocyte filters were measured. Leukocyte filters removed
$90 \%$ of leukocytes in the first $1000 \mathrm{~mL}$ of blood. After filtration of 1500 and $2000 \mathrm{~mL}$ of blood, $88 \%$ and $53 \%$ of leukocytes, respectively, were removed.

\section{Histologic Examination}

Data on histologic examination are given in Figure 8. Microscopic examination revealed no rejection of the transplanted heart. Only scattered ischemic damage (eg, slight 


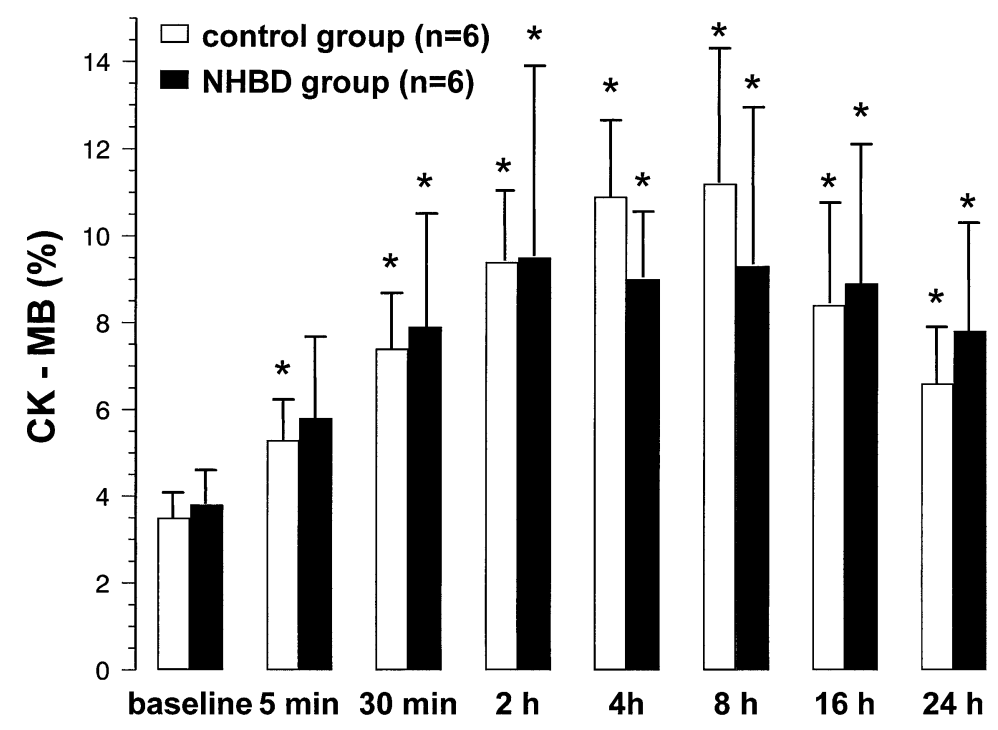

Figure 6. Serum levels of CK-MB before and during the first 24 hours after heart transplantation. ${ }^{*} \boldsymbol{P}<.05$ versus baseline. The peak of CK-MB release was 2 to 8 hours after heart transplantation. There were no significant intergroup differences.

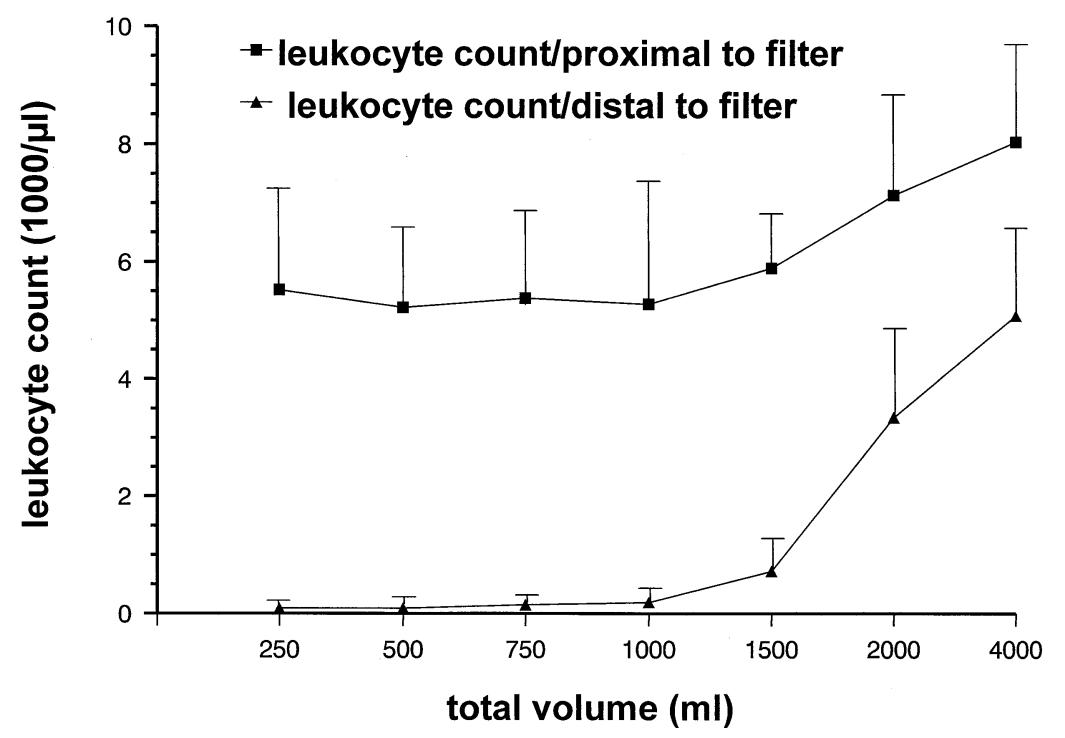

Figure 7. Extraction of leukocytes by leukocyte filters during controlled reperfusion. Flow rate was 200 to 300 $\mathrm{mL} / \mathrm{min}$. After $1000 \mathrm{~mL}$ of total blood volume, the filter becomes less functional.

myocardial edema and leukocyte infiltration without myocytolysis) could be found in the majority of specimens. Differentiation of irreversibly damaged myocardium was possible by means of Luxol fast blue staining. Examination by 2 blinded observers revealed that only $2.6 \% \pm 4.8 \%$ of myocytes in the control group versus $1.8 \% \pm 1.9 \%$ in the NHBD group were damaged irreversibly.

\section{Discussion}

This experimental study shows that successful transplantation of hearts from NHBDs after 30 minutes of normothermic ischemia is possible without remarkable irreversible damage and with equivalent recovery compared with that in hearts harvested from heart-beating donors. For the first time, comprehensive assessment of these hearts 24 hours 


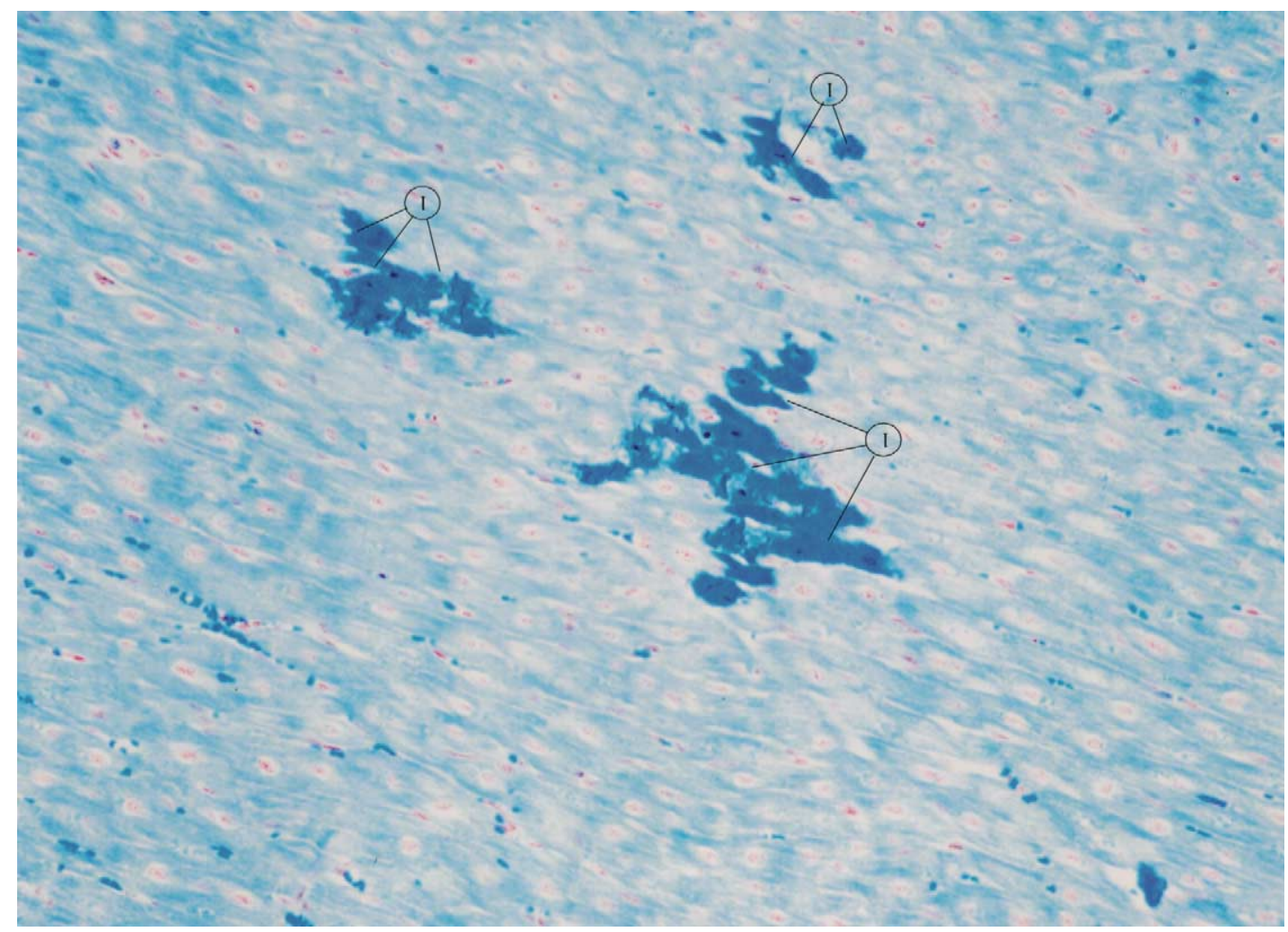

Figure 8. Groups of irreversibly damaged myocytes (1). (Luxol fast blue, original magnification $20 \times$.) In both groups only a few focal lesions, including a maximum of $\mathbf{1 0}$ muscle cells, could be found.

after transplantation has been performed. In summary, the following results could be obtained:

1. There was no significant difference in contractility between the NHBD group and the control group.

2. Regional myocardial blood flow was increased after transplantation in both groups without intergroup differences, indicating preserved function of the vasculature and the endothelium.

3. In both groups there was no significant change in myocardial oxygen consumption 24 hours after transplantation compared with baseline values.

4. Myocardial specific $\mathrm{CK}$ and lactate dehydrogenase levels of the experimental group did not differ significantly versus those of the control group.

5. Histologic examination showed only scattered irreversibly damaged myocardial cells in both groups.

\section{Hemodynamics}

Cardiac output and ejection fraction after transplantation were significantly decreased compared with baseline values in both groups (Table 1). This was associated with a dramatic increase in pulmonary vascular resistance, a common problem after cardiopulmonary bypass in pigs. ${ }^{7}$ PRSW, Ees, dp/dtmax, and dp/dtmin were not diminished after heart transplantation, indicating normal contractile function (Table 2).

In contrast, right ventricular, but not left ventricular, PRSW and Ees were significantly increased. A possible explanation of this phenomenon could be methodical problems related to the enormously increased afterload after transplantation. Interpretation of pressure-volume loops provides reliable assessment of contractility independent of preload conditions, but results can be significantly influenced by changing afterload conditions. ${ }^{8}$ An increase in right ventricular PRSW index and Ees might result from the enhanced afterload after transplantation and might not reflect an increase in myocardial contractility.

\section{Regional Myocardial Blood Flow}

Coronary blood flow was increased 4 and 24 hours after transplantation in both groups (Figure 1). This enhancement might be due to the application of epinephrine and has been observed by other investigators. ${ }^{9,10}$ In contrast, ischemic myocardial damage has been shown to be associated with increased coronary resistance and restricted coronary flow reserve. ${ }^{11,12}$ The finding of increased RMBF in the present study shows no evidence of severe myocardial damage. 


\section{Metabolic Activity}

Myocardial oxygen consumption of porcine myocardium at rest $\left(12 \mathrm{~mL} \times \mathrm{kg}^{-1} \times \mathrm{min}^{-1}\right)$ is comparable with that of human hearts and reflects aerobic metabolism. Measurements 4 and 24 hours after transplantation revealed no significant changes in both groups (Figure 2). After 30 minutes of normothermic ischemia, myocardium was able to extract $75 \%$ of oxygen from blood cardioplegia during the first controlled reperfusion in the donor. Similar results could be obtained after the start of reperfusion during implantation of the donor heart (Figure 5).

Our data indicate full viability and preserved myocardial function after transplantation of these ischemically compromised hearts. Successful transplantation was possible by using a new preservation strategy based on the concept of integrated myocardial protection. ${ }^{13}$ Myocardial preservation strategies must address a broad spectrum of pathophysiologic aspects. In addition to the established principles of controlled reperfusion, further refinements have been used to prevent leukocyte-mediated damage and preserve endothelial function.

\section{Leukocyte Depletion}

Leukocyte filtration of blood cardioplegia has been shown to reduce reperfusion damage in several experimental and clinical studies. ${ }^{14-16}$ Leukocyte filters can remove more than $90 \%$ of blood leukocytes, but our data show that they become less functional after blood delivery of greater than $1000 \mathrm{~mL}$ and have to be exchanged (Figure 7).

\section{Adenosine \\ Damaged hearts exhibit loss of endothelium-dependant fac- tors and reduced nitric oxide formation. Impairment of endothelial function plays an important role in ischemia- reperfusion injury and has been underestimated in previous preservation strategies. ${ }^{17}$ We must consider endothelial stunning and develop efforts to reduce this injury during myocardial protection. ${ }^{18}$ \\ Adenosine has been shown to have broad-spectrum car- dioprotective effects by acting through multiple mecha- nisms on neutrophils, endothelium, and myocytes. ${ }^{4,19}$ \\ Berne ${ }^{20}$ described the key role of adenosine in the auto- regulation of coronary blood flow. Furthermore, because of stimulation of myocardial A1 receptors, adenosine activates adenosine triphosphate-sensitive potassium channels and attenuates myocardial stunning. ${ }^{21}$ Applied as an adjunct to standard cold blood cardioplegia in hearts exposed to 30 minutes of normothermic ischemia, adenosine reversed the postischemic systolic dysfunction. ${ }^{22}$}

\section{Intermittent Reperfusion During Donor Heart Implantation}

Another attempt to minimize myocardial damage in heart transplantation is the application of blood cardioplegia dur- ing implantation of the donor heart. We started antegrade reperfusion with tepid blood cardioplegia $\left(15^{\circ} \mathrm{C}\right)$ after completion of the first anastomosis to avoid the high temperature gradient between the reperfusate and the myocardium. Blood cardioplegia was substrate enriched and supplemented with high doses of HOE 642 and adenosine. Various modifications of early reperfusion with blood cardioplegia have been described. ${ }^{23-25}$ Clinical investigations have shown that intermittent cold blood cardioplegia during implantation is superior to the conventional technique with respect to the incidence of spontaneous defibrillation, return to sinus rhythm, time of mechanical ventilation, and need for inotropic support. ${ }^{23,24}$

\section{Clinical Implications}

The critical shortage of transplantable organs necessitates the use of unconventional donors. Cautious liberalization of donor criteria is justified. The use of NHBDs has been proposed as one way to increase the donor pool for kidneys and livers worldwide. ${ }^{26-29}$ Routine transplantation of islets and lungs from NHBDs can be expected within the near future. ${ }^{30,31}$ Isolated instances of clinical heart transplantation from NHBDs have been reported. ${ }^{32,33}$ The results are encouraging and have increased the awareness of these types of donors for organ procurement. The use of marginal donors should be cautiously pursued as one way to help alleviate the current shortage of donor organs.

As more experience in the use of NHBD is gathered, this should serve as an impetus to further expand our knowledge of biologic or physiologic alteration in these donors, which can be minimized by newer technology. Refinements of the preservation strategy are necessary to provide successful transplantation of hearts from marginal donors or NHBDs. Traditional myocardial protection techniques are sufficient for good donor hearts and short ischemic times. Liberalization of donor criteria requires broader use of controlled reperfusion, leukocyte depletion, and other protective additives in heart transplantation.

\section{Limitations of the Study}

Increased afterload after heart transplantation, as indicated by pulmonary and systemic vascular resistance, might influence contractility parameters (eg, cardiac output and PRSW). Therefore comparison between hemodynamic baseline data and posttransplant data bears problems. In contrast, comparison between the NHBD group and the control group is appropriate. Pharmacologic interventions to decrease pulmonary vascular resistance would have been helpful to avoid these problems and to adopt the model more to the clinical setting.

NHBD hearts were obtained after arresting the hearts by means of exsanguination. In the face of a potential clinical setting with NHBDs (so-called controlled NHBDs), it has to 
be considered that donors are taken off the ventilator. There is some evidence that death from asphyxia causes more myocardial damage than death from exsanguination. ${ }^{34}$ Further experiments are necessary with respect to the detrimental effects of anoxia and higher filling pressures to evaluate the efficiency of our myocardial preservation strategy.

Moreover, the detrimental effects of brain death are not considered in this experimental model. Possibly, brain death of the donor could further impair the function of the transplanted hearts.

In conclusion, transplantation of ischemically compromised hearts harvested after 30 minutes of normothermic ischemia is possible in this experimental model without relevant irreversible damage. Contractility, myocardial perfusion, metabolic activity, and histologic damage are comparable with those of hearts harvested from beating-heart donors.

We acknowledge the statistical review by Mr Manfred Olschewski, MSc, Institute of Medical Biometry of the AlbertLudwigs-University Freiburg.

\section{References}

1. Hosenpud JD, Bennett LE, Keck BM, Boucek MM, Novick RJ. The registry of the International Society for Heart and Lung Transplantation: Seventeenth official report-2000. J Heart Lung Transplant. 2000; 19:909-31.

2. Martin J, Sarai K, Yoshitake M, et al. Orthotopic transplantation of pig hearts harvested after $30 \mathrm{~min}$ of normothermic ischemia: controlled reperfusion with blood cardioplegia containing the $\mathrm{Na}^{+}-\mathrm{H}^{+}$-exchange inhibitor HOE 642. Eur J Cardiothorac Surg. 1998;14:607-14.

3. Martin J, Sarai K, Yoshitake M, et al. Successful orthotopic pig heart transplantation from non-heart-beating donors. J Heart Lung Transplant. 1999;18:597-606.

4. Vinten-Johansen J, Thourani VH, Ronson RS, et al. Broad-spectrum cardioprotection with adenosine. Ann Thorac Surg. 1999;68:1942-8.

5. Fluorescent Microsphere Resource Center information Web site. Manual for using fluorescent microspheres to measure regional organ perfusion. University of Washington, Division of Pulmonary and Critical Care Medicine, Seattle. Available at: http://fmrc.pulmcc. washington.edu/fmrc/fmrc.html. Accessed December 12, 1999.

6. van Oosterhout MFM, Willigers HMM, Reneman RS, Prinzen FW. Fluorescent microspheres to measure organ perfusion: validation of a simplified sample processing technique. Am J Physiol Heart Circ Physiol. 1995;269:H725-33.

7. Swindle M. Porcine models in surgical research: an overview. In: Tumbleson ME, editor. Swine in biomedical research. New York: Plenum Press; 1986. p. 135-42.

8. Kass DA, Maughan WL. From "Emax" to pressure-volume relations: a broader view. Circulation. 1988;77:1203-12.

9. Yanagi S, Takeuchi K, Takeda T, Ishikawa M, Miura I. Comparison of the effects of dobutamine and isoproterenol in ischemic hearts by phosphorous-31 nuclear magnetic resonance spectroscopy. Jpn Circ J. 1994;S8:338-50.

10. Deussen A, Flesche CW, Lauer T, Sonntag M, Schrader J. Spatial heterogeneity of blood flow in the dog heart. II. Temporal stability in response to adrenergic stimulation. Pflugers Arch. 1996;432:451-61.

11. Parker PE, Bashour FA, Downey HF, Kechejian SJ, Williams AG. Coronary hemodynamics during reperfusion following acute coronary ligation in dogs. Am Heart J. 1975;90:593-9.

12. Heyndrickx GR, Baig H, Nellens P, Leusen I, Fishbein MC, Vatner SF. Depression of regional blood flow and wall thickening after brief coronary occlusion. Am J Physiol. 1978;234:H653-9.
13. Buckberg GD. Myocardial protection: an overview. Semin Thorac Cardiovasc Surg. 1993;5:98-106.

14. Pearl JM, Drinkwater DC, Laks H, Capouya ER, Gates RN. Leukocyte-depleted reperfusion of transplanted human hearts: a randomized, double-blind clinical trial. J Heart Lung Transplant. 1992;11:1082-92.

15. Byrne JG, Appleyard RF, Lee CC, et al. Controlled reperfusion of the regionally ischemic myocardium with leukocyte-depleted blood reduces stunning, the no-reflow phenomenon, and infarct size. $J$ Thorac Cardiovasc Surg. 1992;103:66-72.

16. Roth M, Kraus B, Scheffold T, Reuthebuch O, Klövekorn WP, Bauer EP. The effect of leukocyte-depleted blood cardioplegia in patients with severe ventricular dysfunction: a randomized, double-blind study. J Thorac Cardiovasc Surg. 2000;120:642-50.

17. Pearl JM, Laks H, Drikwater DC, et al. Loss of endothelium-dependent vasodilatation and nitric oxide release after myocardial protection with University of Wisconsin solution. J Thorac Cardiovasc Surg. 1994;107:257-64.

18. Buckberg GD. Endothelial and myocardial stunning. J Thorac Cardiovasc Surg. 2000;120:640-1.

19. Olafsson B, Forman MB, Puett DW, et al. Reduction of reperfusion injury in the canine preparation by intracoronary adenosine: importance of the endothelium end the no-reflow phenomenon. Circulation. 1987;76:1135-45.

20. Berne RM. The role of adenosine in the regulation of coronary blood flow. Circ Res. 1980;47:807-13.

21. Auchampach JA, Maruyama M, Carero I, Gross GJ. Pharmacological evidence for a role of ATP-dependent potassium channels in myocardial stunning. Circulation. 1992;86:311-9.

22. Hudspeth DA, Nakanishi K, Vinten-Johansen J, et al. Adenosine in blood cardioplegia prevents postischemic dysfunction in ischemically injure hearts. Ann Thorac Surg. 1994;58:1637-44.

23. Nataf P, Pavie A, Bracamontes L, Bors V, Cabrol C, Gandjbakhch I. Myocardial protection by blood cardioplegia and warm reperfusion in heart transplantation. Ann Thorac Surg. 1992;53:526-7.

24. Soots G, Crepin F, Prat A. Cold blood cardioplegia and warm cardioplegic reperfusion in heart transplantation. Eur J Cardiothorac Surg. 1991;5:400-5.

25. Pradas G, Cuenca J, Juffe A. Continuous warm reperfusion during heart transplantation. J Thorac Cardiovasc Surg. 1996;11:784-90.

26. Fung JJ. Use of non-heart-beating donors. Transplant Proc. 2000;32: 1510-1.

27. Light JA, Sasaki TM, Ayuino AQ, Barhyte DY, Gage F. Excellent long-term graft survival with kidneys from the uncontrolled non-heartbeating donor. Transplant Proc. 2000;32:186-7.

28. Gerstenkorn C, Oliveira D, MacPhee I, Chang R. Non-heart-beating donors for renal transplantation. Lancet. 2000;356:1854.

29. Reich DJ, Munoz SJ, Rothstein KD, et al. Controlled non-heartbeating donor liver transplantation: a successful single center experience, with topic update. Transplantation. 2000;70:1159-66.

30. Clayton HA, Swift SM, Turner JM, James RF, Bell PR. Non-heartbeating organ donors: a potential source of islets for transplantation? Transplantation. 2000;69:2094-8.

31. Wierup P, Andersen C, Janciauskas D, Bolys R, Sjoberg T, Steen S. Bronchial healing, lung parenchymal histology, and blood gases one month after transplantation of lungs topically cooled for 2 hours in the non-heart-beating cadaver. J Heart Lung Transplant. 2000;19:270-6.

32. Barnard CN. A human cardiac transplant: an interim reperot of a successful operation performed at Groote Schuur Hospital, Cape Town. S Afr Med J. 1967;41:1271-5.

33. Dureau G. Heart transplant from non-beating heart donor. Past experience and report of one clinical case. In: Touraine JL, Traeger J, Betuel H, Dubernard JM, Revillard JP, Dupuy C, editors. Organ shortage: the solutions. Dordrecht: Kluwer Academic Publishers; 1995. p. 61-6.

34. Cooper DKC. The donor heart. The present position with regard to resuscitation, storage, and assessment of viability. J Surg Res. 1976; 21:363-81.

\section{Discussion}

Dr Frank W. Sellke (Boston, Mass). You had 2 groups of animals, is that correct? One you harvested, the control group, and 